\title{
Psychometric analysis of the questionnaires for the assessment of upper limbs available in their Italian version: a systematic review of the structural and psychometric characteristics
}

\author{
Luca Barni ${ }^{1,4}$, María Ruiz-Muñoz ${ }^{2,3^{*}}$ D, Manuel Gonzalez-Sanchez ${ }^{3,4}$, Antonio I. Cuesta-Vargas ${ }^{3,4,5}$,
} Jose Merchan-Baeza ${ }^{6}$ and Marco Freddolini ${ }^{7}$

\begin{abstract}
Introduction: There is no systematic review that analyzes the psychometric properties of questionnaires in Italian. Previous studies have analyzed the psychometric characteristics of instruments for the measurement of pathologies of upper limbs and their joints in different languages. The aim of the present study was to analyze the psychometric properties of the questionnaires published in Italian for the evaluation of the entire upper limb or some of its specific regions and related dysfunctions.

Evidence acquisition: For the development of this systematic review, the following databases were used: PubMed, Scopus, Cochrane, Dialnet, Cinahl, Embase and PEDro. The selection criteria used in this study were: studies of transcultural adaptation to Italian of questionnaires oriented to the evaluation of upper limbs or any of their structures (specifically shoulder, elbow and wrist/hand), and contribution of psychometric variables of the questionnaire in its Italian version.

Evidence synthesis: After reading the titles and applying the inclusion and exclusion criteria to the complete documents, 16 documents were selected: 3 for the upper limb, 8 for the shoulder, 1 for the elbow and 4 for the wrist and hand. The cross-sectional psychometric variables show levels between good and excellent in all the questionnaires. Longitudinal psychometric variables had not been calculated in the vast majority of the analyzed questionnaires.
\end{abstract}

Conclusions: Italian versions of the questionnaires show good basic structural and psychometric characteristics for the evaluation of patients with musculoskeletal disorders of the upper limb and its joints (shoulder, elbow and wrist/ hand).

Keywords: Upper Limb, Review, Psychometrics, Questionnaires, Pathology

*Correspondence: marumu@uma.es

${ }^{2}$ Department of Nursing and Podiatry, Faculty of Health Sciences,

University of Málaga, Arquitecto Francisco Peñalosa, 3, 29071 Málaga, Spain

Full list of author information is available at the end of the article

\section{Introduction}

Upper limb neuromusculoskeletal disorders are a common musculoskeletal complaint, with lifetime prevalence in developed nations of up to $67 \%$ [1]. It has been estimated that upper limb disorders cause at least $10 \%$ of the consultations of physiotherapists [2], generating

(c) The Author(s) 2021. Open Access This article is licensed under a Creative Commons Attribution 4.0 International License, which permits use, sharing, adaptation, distribution and reproduction in any medium or format, as long as you give appropriate credit to the original author(s) and the source, provide a link to the Creative Commons licence, and indicate if changes were made. The images or other third party material in this article are included in the article's Creative Commons licence, unless indicated otherwise in a credit line to the material. If material is not included in the article's Creative Commons licence and your intended use is not permitted by statutory regulation or exceeds the permitted use, you will need to obtain permission directly from the copyright holder. To view a copy of this licence, visit http://creativecommons.org/licenses/by/4.0/. The Creative Commons Public Domain Dedication waiver (http://creativeco mmons.org/publicdomain/zero/1.0/) applies to the data made available in this article, unless otherwise stated in a credit line to the data. 
a very high indirect health expense, due to their long recovery period, and thus leading to the loss of functional and working capacity [3].

In the clinical practice, there are objective and subjective instruments for the assessment and monitoring of these pathologies $[4,5]$. Questionnaires are a necessary part of the process of managing patients' health. These tools are used to a large extent to objectively determine any response or change on the health status and function of the patient, with the latter reflecting his/her health status [4-6]. They help clinicians and researchers to monitor the situation of patients and determine whether they have changed [4-6]. As this form of patient-centered process management has been adopted and improved in the field of trauma over the past two decades, there has been an increase in the use of specific questionnaires for certain areas of the body. Consequently, they are frequently used as the standard protocol for the measurement and management of the functional status [6]. It is necessary that all measurement instruments used in the clinical practice and in research have been the subject of a validation study in which their psychometric characteristics are identified [7].

Italian is one of the official languages of the European Union, and it is spoken in eight countries [8]. Around the world, more than 65 million people speak Italian, becoming, recently, the fourth most studied language in the world [8].

Previous reviews have analyzed the psychometric characteristics of instruments for the measurement of pathologies of upper limbs and their joints in different languages [9-15]. In addition, a systematic review that analyzes the psychometric characteristics of the questionnaires in Italian for the cervical and lumbar spine has been published [16]. However, no systematic review has analyzed the psychometric characteristics of Italian tools for the assessment and follow-up of patients with upper limb disorders.

The aim of the present study was to analyze the psychometric properties of the questionnaires published in Italian for the evaluation of the entire upper limb or some of its specific regions and related dysfunctions.

\section{Methods and materials Protocol}

This systematic review was carried out in accordance with the general guidelines and recommendations made by Preferred Reporting Items for Systematic Reviews and Meta-analyses (PRISMA) [7]. This systematic review was recorded at PROSPERO with the following reference number: CRD42020164002.

\section{Sources and search}

The search was carried out in 7 databases, specifically: PubMed, Cochrane, PEDro, Cinahl, Scopus, Dialnet and Embase. The searches focused on the bibliographic review referring to the upper limbs or to any of the joints/segments included in this body region. A combination of the following keywords was carried out, using the Boolean operators "OR" and "AND": upper limb, wrist, hand, elbow, shoulder, questionnaire, Italian, psychometric, validity and validation. No filter was used in the search.

\section{Eligibility criteria}

The selection criteria used in this study were: studies of transcultural adaptation to Italian of questionnaires oriented to the evaluation of upper limbs or any of their structures (specifically shoulder, elbow and wrist/ hand), and contribution of psychometric variables of the questionnaire in its Italian version. Articles that were published in languages other than English or Italian were excluded. Moreover, in the case of questionnaires with different updates, we selected the most recent version of the questionnaire validated in Italian. Articles published until November 30th, 2020, were considered.

\section{Study selection}

After performing the bibliographic search, studies were first filtered based on the title and abstract. Subsequently, the selected documents were read in-depth in order to be included or excluded from the study.

The bibliographic search and study selection were carry out by two authors, who were mutually blinded in each of the different stages in which the search and selection of the studies was structured. In cases of discrepancy, a third author (with more than 15 years of experience in the identification and selection of scientific documents), decided whether the document was finally selected or not.

\section{Synthesis of results and data extraction}

From each article, both the structural characteristics and the psychometric aspects of each of the questionnaires were extracted. The structural characteristics extracted were: full name, acronym, author and date of the adaptation to the Italian language, what it measures, number of items, completion time, result scale and cost. The psychometric aspects were: Standard Error of Measurement (SEM), Minimum Detectable Change (MDC), test-retest reliability, internal consistency, criterion validity, construct validity and sensitivity to changes. In addition, 
cross-cultural validity was assessed in each questionnaire [7].

\section{Results}

\section{Search and selection of documents}

Figure 1 shows the flowchart of the search and selection papers. After the initial identification of 1050 studies and the removal of duplicates, 798 documents were selected. These were classified in the following manner: 327 documents for the upper limbs, 176 for the shoulder, 88 for the elbow and 207 for the wrist and hand. After reading the titles and applying the inclusion and exclusion criteria to the complete documents, 16 documents were selected.

These included three for the upper limb (the Disability of the Arm, Shoulder and Hand [17], the Cold Intolerance Symptom Severity questionnaire [18] and the Upper
Limb Functional Index [19]), eight for the shoulder, one for the elbow and four for the wrist and hand (see Fig. 1 for more details).

\section{Structural characteristics}

From a structural point of view, Tables 1, 2, 3 and 4 present the structural characteristics of the questionnaires for the upper limbs, shoulder, elbow and hand/wrist, respectively. For the upper limbs in particular (Table 1), the number of items of the identified questionnaires ranged from 14 to 30 , the number of sub-categories ranged from 0 to 7 , the time to complete the questionnaires ranged from 5 to $10 \mathrm{~min}$ and all the questionnaires were free.

For their part, the questionnaires identified for the specific assessment of the shoulder had a number of items

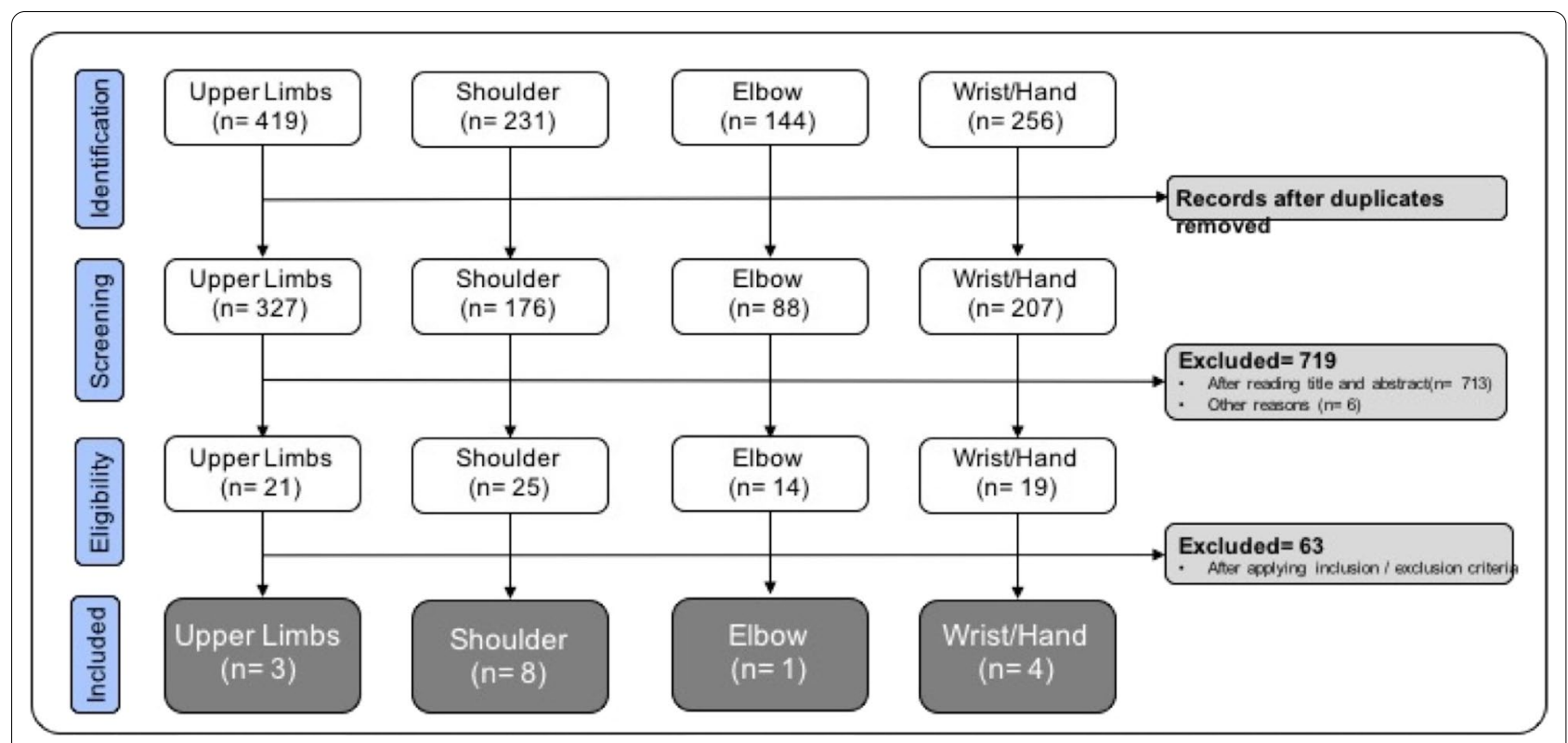

Fig. 1 Flow chart of the search, selection and inclusion of the questionnaires for the evalution of the upper limb avaibale in Italian version

Table 1 Structural characteristics of the questionnaires identified for the upper limb

\begin{tabular}{|c|c|c|c|c|c|c|}
\hline Name & Acronym & No of items & Sub-category & Time to complete & Measurement & Cost \\
\hline Disability of the Arm, Shoulder and Hand [7] & DASH & 30 & $\begin{array}{l}\text { DASH function/symptoms } \\
\text { DASH sport/music } \\
\text { DASH work }\end{array}$ & $10 \mathrm{~min}$ & $0-100$ & Free \\
\hline $\begin{array}{l}\text { Cold Intolerance Symptom Severity questionnaire } \\
\text { [17] }\end{array}$ & CISSq & 14 & $\begin{array}{l}\text { Pain } \\
\text { Numbness } \\
\text { Stiffness } \\
\text { Weakness } \\
\text { Aching } \\
\text { Swelling } \\
\text { Skin colour change }\end{array}$ & 10 & $0-100$ & Free \\
\hline Upper Limb Functional Index [18] & ULFI & 25 & - & 5 & $0-100$ & Free \\
\hline
\end{tabular}


Table 2 Structural characteristics of the questionnaires identified for the shoulder

\begin{tabular}{|c|c|c|c|c|c|c|}
\hline Name & Acronym & No of items & Sub-category & Time to complete & Measurement & Cost \\
\hline American Shoulder and Elbow Surgeons [24] & ASES & 11 & $\begin{array}{l}\text { Pain } \\
\text { Function }\end{array}$ & $5 \mathrm{~min}$ & 100 & Free \\
\hline $\begin{array}{l}\text { Kerlan-Jobe Orthopaedic Clinic Shoulder and } \\
\text { Elbow [21] }\end{array}$ & KJOCSE & 10 & & $10 \mathrm{~min}$ & 100 & Free \\
\hline Nottingham Clavicle Score [19] & NCS & 10 & $\begin{array}{l}\text { Pain in bed at night } \\
\text { Ability to lift heavy objects and } \\
\text { overhead strength } \\
\text { Cosmetic satisfaction } \\
\text { Movements and clicking within } \\
\text { the shoulder } \\
\text { Ingling and numbness in the } \\
\text { arm and neck } \\
\text { Heavy or dragging sensations } \\
\text { in the arm }\end{array}$ & $10 \mathrm{~min}$ & 100 & Free \\
\hline Oxford Shoulder Score [20] & OSS & 12 & - & $3-5 \min$ & $12-60$ & Free \\
\hline Rotator Cuff Quality of Life [25] & RC-QoL & 30 & $\begin{array}{l}\text { Physical alterations } \\
\text { Job } \\
\text { Recreational/sports activities } \\
\text { Social aspects } \\
\text { Lifestyle }\end{array}$ & $10-15 \min$ & $0-300$ & Free \\
\hline Simple Shoulder Test [26] & SST & 12 & - & $5 \mathrm{~min}$ & $0-100$ & Free \\
\hline Shoulder Pain and Disability Index [27] & SPADI & 13 & $\begin{array}{l}\text { Pain } \\
\text { Function }\end{array}$ & $5 \mathrm{~min}$ & $0-100$ & Free \\
\hline University of California_Los Angeles [26] & UCLA & 2 & $\begin{array}{l}\text { Pain } \\
\text { Function }\end{array}$ & $3 \min$ & $\begin{array}{l}0-10 \\
0-10\end{array}$ & Free \\
\hline $\begin{array}{l}\text { Western Ontario Osteoarthritis of the Shoulder } \\
\text { [22] }\end{array}$ & wOOS & 19 & $\begin{array}{l}\text { Physical symptoms } \\
\text { Sport/recreation/work } \\
\text { Lifestyle } \\
\text { Emotions }\end{array}$ & $10 \mathrm{~min}$ & 0-1900 & Free \\
\hline Western Ontario Shoulder Instability [23] & WOSI & 21 & $\begin{array}{l}\text { Physical symptoms } \\
\text { Sport/recreation/work function } \\
\text { Lifestyle function } \\
\text { Emotional well-being }\end{array}$ & $10 \mathrm{~min}$ & $0-2100$ & Free \\
\hline
\end{tabular}

Table 3 Structural characteristics of the questionnaires identified for the elbow

\begin{tabular}{|c|c|c|c|c|c|c|}
\hline Name & Acronym & No of items & Sub-category & Time to complete & Measurement & Cost \\
\hline $\begin{array}{l}\text { Patient-rated tennis elbow evalua- } \\
\text { tion [28] }\end{array}$ & PRTEE & 15 & $\begin{array}{l}\text { Pain } \\
\text { Degree of difficulty (specific activi- } \\
\text { ties) } \\
\text { Degree of difficulty (usual) }\end{array}$ & 10 & 0 (best)-100 (worst) & Free \\
\hline
\end{tabular}

Table 4 Structural characteristics of the questionnaires identified for the wrist

\begin{tabular}{|c|c|c|c|c|c|c|}
\hline Name & Acronym & No of items & Sub-category & Time to complete & Measurement & Cost \\
\hline Functional index for hand osteoarthritis [29] & $\mathrm{FIHOA}$ & 10 & - & $5 \mathrm{~min}$ & $0-30$ & Free \\
\hline Hands Mobility in Scleroderma [30] & HAMIS & 9 & - & $15 \min$ & 0 (best)-27 (worst) & Free \\
\hline Hand functional disability scale [31] & HFDS & 18 & $\begin{array}{l}\text { Hand ability in: } \\
\text { The kitchen } \\
\text { Dressing } \\
\text { Personal hygiene } \\
\text { Office tasks } \\
\text { Other general } \\
\text { items }\end{array}$ & $10 \mathrm{~min}$ & $0-90$ & Free \\
\hline Patient-rated wrist/hand evaluation [32] & PRWHE & 15 & $\begin{array}{l}\text { Pain } \\
\text { Function }\end{array}$ & $10 \mathrm{~min}$ & $0-100$ & Free \\
\hline
\end{tabular}


that ranged from 2 to 30 , the number of subcategories ranged from zero to six, the time to complete them ranged from 3 to $15 \mathrm{~min}$, and all the questionnaires can be used free of charge (Table 2). Regarding the evaluation of the elbow, a single free questionnaire was identified, which had 15 items and 3 sub-scales and requires approximately $10 \mathrm{~min}$ to complete (Table 3 ).

Finally, Table 4 shows the questionnaires for the hand and the wrist. The number of items in these questionnaires ranged from 9 to 18 , the sub-categories ranged from 0 to 5 and the time to complete them ranged from 5 to $15 \mathrm{~min}$. All the identified questionnaires can be used free of charge.

\section{Psychometric characteristics}

The psychometric characteristics of the questionnaires are presented in Tables 5, 6, 7 and 8 for the upper limbs, shoulder, elbow and hand/wrist, respectively. Specifically, Table 5 shows the psychometric characteristics of the questionnaires for the upper limbs. It presents the reliability of all the questionnaires, ranging from good to excellent. Similarly, the internal consistency was excellent for all the questionnaires, while two questionnaires (CISS and ULFI) $[18,19]$ perform an analysis of error measures and one questionnaire (DASH) analyzes the difficulty of the response [17].

Table 6 shows the results of the psychometric characteristics of the questionnaires aimed at evaluating the shoulder. Specifically, 8 of the 10 selected questionnaires present excellent reliability, which is between poor and excellent for NCS [20] and between moderate and excellent for the Oxford Shoulder Score [21]. The internal consistency presents excellent results in 7 of the 10 analyzed questionnaires, while in the other 3 questionnaires this psychometric variable is not shown.
To analyze the criterion validity, the SF-36 and DASH questionnaires have been frequently used, each of them in four validation studies. In 3 of the 10 studies, error measures (SEM and MDC) were analyzed, specifically in KJOCSE [22], WOOS [23] and WOSI [24]. In addition, in the latter two, criteria of responsiveness (SRM-standardized response mean) were also analyzed, being the only two that assessed this psychometric characteristic among all the identified questionnaires for the evaluation of the shoulder.

Table 7 presents the psychometric characteristics of the only questionnaire identified in Italian for the evaluation of the elbow. Specifically, the reliability of this questionnaire is 0.95 in the short term, and 0.93 in the long term. In addition, the internal consistency is 0.90 and the DASH questionnaire was used, again, for criterion validity. This questionnaire is one of the few that perform an analysis of sensitivity and specificity. The sensitivity is 0.94 while the specificity is 0.78 . In addition, the SEM was analyzed both in the short and long term, as well as the ease of response, analyzing both the ES and the SRM.

Table 8 presents the psychometric characteristics of the questionnaires in Italian aimed at evaluating the hand and the wrist. The test-retest reliability of these standardized questionnaires was calculated in three of the four selected documents, showing values above 0.95 in all cases. On the other hand, although the internal consistency is excellent, it decreases slightly, showing values between 0.87 and 0.96 . For criterion validity, again, the SF-36 questionnaire is the most used, since it was used in three of the four selected questionnaires. None of them analyze sensitivity, error measurement or responsiveness.

Table 5 Psychometric variables of the selected questionnaires for the upper limb

\begin{tabular}{|c|c|c|c|c|c|c|c|c|}
\hline Name & $\begin{array}{l}\text { Reliability test- } \\
\text { restest }\end{array}$ & $\begin{array}{l}\text { Inter-observer } \\
\text { reliability }\end{array}$ & $\begin{array}{l}\text { Internal } \\
\text { consistency }\end{array}$ & $\begin{array}{l}\text { Validity of } \\
\text { criteria }\end{array}$ & Sensitivity & SEM & MDC & $\begin{array}{l}\text { Responsiveness } \\
\text { (SRM- } \\
\text { standardised } \\
\text { response mean) }\end{array}$ \\
\hline $\begin{array}{l}\text { Disability of the } \\
\text { Arm, Shoulder } \\
\text { and Hand [7] }\end{array}$ & $\begin{array}{l}\text { DASH-FS: } 0.89 \\
\text { DASH-SM: } 0.75 \\
\text { DASH-W: } 0.84\end{array}$ & - & $\begin{array}{l}\text { DASH-FS: } 0.90 \\
\text { DASH-SM: } 0.82 \\
\text { DASH-W: } 0.85\end{array}$ & $\begin{array}{l}\text { DASH-FS: } \\
0.27-0.70 \\
\text { DASH-SM: } \\
0.01-0.5 \\
\text { DASH-W: } \\
0.36-0.63\end{array}$ & - & - & - & 0.90 \\
\hline $\begin{array}{l}\text { Cold Intoler- } \\
\text { ance Symptom } \\
\text { Severity ques- } \\
\text { tionnaire [17] }\end{array}$ & CISS: 0.96 & CISS: 0.34-0.92 & $\begin{array}{l}\text { CISS total: } 0.93 \\
\text { CISS scales: } \\
0.58-0.91\end{array}$ & $\begin{array}{l}\text { DN4: } 0.73 \\
\text { MRC: } 0.44-0.61\end{array}$ & - & 4.07 points & $\begin{array}{l}\text { MDC90: } 9.45 \\
\text { MDC95: } 11.30\end{array}$ & - \\
\hline $\begin{array}{l}\text { Upper Limb } \\
\text { Functional } \\
\text { Index [18] }\end{array}$ & ULFI: 0.94 & - & ULFI: 0.90 & DASH:0 81 & - & 5 points & MDC90: 12 & - \\
\hline
\end{tabular}


Table 6 Psychometric variables of the selected questionnaires for the shoulder

\begin{tabular}{|c|c|c|c|c|c|c|c|c|}
\hline Name & $\begin{array}{l}\text { Reliability test- } \\
\text { restest }\end{array}$ & $\begin{array}{l}\text { Inter- } \\
\text { observer } \\
\text { reliability }\end{array}$ & $\begin{array}{l}\text { Internal } \\
\text { consistency }\end{array}$ & Validity of criteria & Sensitivity & SEM & MDC & $\begin{array}{l}\text { Responsiveness } \\
\text { (SRM-standardised } \\
\text { response mean) }\end{array}$ \\
\hline $\begin{array}{l}\text { American Shoulder } \\
\text { and Elbow Surgeons } \\
{[24]}\end{array}$ & 0.91 & - & 0.85 & $\begin{array}{l}\text { OSQ: } 0.78 \\
\text { DASH: }-0.92 \\
\text { SF-36: } 0.20-0.60\end{array}$ & - & - & - & - \\
\hline $\begin{array}{l}\text { Kerlan-Jobe Ortho- } \\
\text { paedic Clinic Shoul- } \\
\text { der and Elbow [21] }\end{array}$ & 0.99 & - & 0.910 & DASH: - 0.697 & - & 0.81 & 2.42 & - \\
\hline $\begin{array}{l}\text { Nottingham Clavicle } \\
\text { Score [19] }\end{array}$ & $0.29-0.90$ & - & 0.86 & $\begin{array}{l}\text { OSS: }-0.84 \\
\text { DASH: }-0.87 \\
\text { SF-36: } 0.19-0.74\end{array}$ & - & - & - & - \\
\hline $\begin{array}{l}\text { Oxford Shoulder } \\
\text { Score }[20]\end{array}$ & $0.57-0.82$ & 0.97 & 0.95 & $\begin{array}{l}\text { UCLA: } 0.67 \\
\text { Constant-Murley: } \\
0.73 \\
\text { SF-36: } 0.40-0.74\end{array}$ & - & - & - & - \\
\hline $\begin{array}{l}\text { Rotator Cuff Quality } \\
\text { of Life [25] }\end{array}$ & 0.94 & - & 0.95 & - & - & - & - & - \\
\hline $\begin{array}{l}\text { University of Califor- } \\
\text { nia-Los Angeles } \\
\text { [26] }\end{array}$ & $>0.89$ & - & - & $\begin{array}{l}\text { SPADI: }>0.91 \\
\text { SST: }>0.91\end{array}$ & - & - & - & - \\
\hline $\begin{array}{l}\text { Shoulder Pain and } \\
\text { Disability Index [27] }\end{array}$ & $>0.89$ & - & - & $\begin{array}{l}\text { UCLA: }>0.91 \\
\text { SST: }>0.91\end{array}$ & - & - & - & - \\
\hline $\begin{array}{l}\text { Simple Shoulder Test } \\
{[26]}\end{array}$ & $>0.89$ & - & - & $\begin{array}{l}\text { SPADI: }>0.91 \\
\text { UCLA: }>0.91\end{array}$ & - & - & - & - \\
\hline $\begin{array}{l}\text { Western Ontario } \\
\text { Osteoarthritis of the } \\
\text { Shoulder [22] }\end{array}$ & 0.96 & - & 0.910 & DASH: 0.73 & - & 0.80 & 2.22 & $\begin{array}{l}\text { Physical symptoms: } \\
0.98 \\
\text { Sport/recreation/work: } \\
1.30 \\
\text { Lifestyle: } 1.13 \\
\text { Emotions: } 0.81 \\
\text { Total:1.11 }\end{array}$ \\
\hline $\begin{array}{l}\text { Western Ontario } \\
\text { Shoulder Instability } \\
\text { [23] }\end{array}$ & $\begin{array}{l}\text { 0.95-Short term } \\
\text { 0.93-Medium term }\end{array}$ & - & 0.93 & $\begin{array}{l}\text { DASH: } 0.79 \\
\text { SF-36: } 0.11\end{array}$ & - & 0.71 & 1.96 & WOSI: 1.57 \\
\hline
\end{tabular}

Table 7 Psychometric variables of the selected questionnaires for the elbow

\begin{tabular}{|c|c|c|c|c|c|c|c|c|}
\hline Name & $\begin{array}{l}\text { Reliability test- } \\
\text { restest }\end{array}$ & $\begin{array}{l}\text { Inter-observer } \\
\text { reliability }\end{array}$ & $\begin{array}{l}\text { Internal } \\
\text { consistency }\end{array}$ & $\begin{array}{l}\text { Validity of } \\
\text { criteria }\end{array}$ & $\begin{array}{l}\text { Sensitivity/ } \\
\text { specificity }\end{array}$ & SEM & MDC & Responsiveness \\
\hline $\begin{array}{l}\text { Patient-Rated } \\
\text { Tennis Elbow } \\
\text { Evaluation [28] }\end{array}$ & $\begin{array}{l}0.95 \text { short term } \\
0.93 \text { long-term }\end{array}$ & - & 0.95 & $\begin{array}{l}\text { DASH } \\
\text { Overall Score: } \\
0.84 \\
\text { Pain: } 0.77 \\
\text { Functional Abil- } \\
\text { ity: } 0.79\end{array}$ & $\begin{array}{l}\text { Sensitivity: } 0.94 \\
\text { Specificity: } 0.78\end{array}$ & $\begin{array}{l}2.68 \text { short term } \\
3.25 \text { long-term }\end{array}$ & - & $\begin{array}{l}\text { ES: } 2.0 \\
\text { SRM: } 2.3\end{array}$ \\
\hline
\end{tabular}

\section{Cross-cultural validity}

Table 9 presents the analysis of the cross-cultural validity for all the questionnaires included in the study, following the different items present in the COSMIN guide for the evaluation of this characteristic [7]. It can be seen how all the selected questionnaires carry out a cross-cultural translation process following the recommendations of the literature, however, in the cross-cultural population process, how none of them performed a confirmatory factor analysis, only one presented an adequate one. sample coma and 11 of them carried out a pre-evaluation of the questionnaire before being used with a larger sample. For more details on the cross-cultural validation evaluation, see Table 9. 
Table 8 Psychometric variables of the selected questionnaires for the wrist

\begin{tabular}{|c|c|c|c|c|c|c|c|}
\hline Name & $\begin{array}{l}\text { Reliability test- } \\
\text { restest }\end{array}$ & $\begin{array}{l}\text { Inter- } \\
\text { observer } \\
\text { reliability }\end{array}$ & Internal consistency & Validity of criteria & SEM & MDC & $\begin{array}{l}\text { Responsiveness } \\
\text { (SRM—standardised } \\
\text { response mean) }\end{array}$ \\
\hline $\begin{array}{l}\text { Functional index for } \\
\text { hand osteoarthritis } \\
{[29]}\end{array}$ & $\begin{array}{l}0.955 \\
(0.767-0.979)\end{array}$ & - & 0.87 & $\begin{array}{l}\text { VAS_pain: } 0.488 \\
\text { HAQ: } 0.609 \\
\text { SF-36: }(-0.283)- \\
(-0.637)\end{array}$ & - & - & - \\
\hline $\begin{array}{l}\text { Hands Mobility in } \\
\text { Scleroderma [30] }\end{array}$ & $\begin{array}{l}0.99 \\
\text { (both hands) }\end{array}$ & - & $\begin{array}{l}0.94 \text { right hand } \\
0.93 \text { left hand }\end{array}$ & $\begin{array}{l}\text { SF-36-PSI: }-0.36 \\
\text { SF-36-MSI: }-0.36\end{array}$ & - & - & - \\
\hline $\begin{array}{l}\text { Hand functional dis- } \\
\text { ability scale [31] }\end{array}$ & $\begin{array}{l}0.96 \\
(0.83-0.97)\end{array}$ & - & $\begin{array}{l}0.872 \\
(0.637-0.928)\end{array}$ & HAQ: 0.81 & - & - & - \\
\hline $\begin{array}{l}\text { Patient-rated wrist/ } \\
\text { hand evaluation [32] }\end{array}$ & - & - & 0.96 & $\begin{array}{l}\text { DASH: } 0.80-0.81 \\
\text { SF-36: }(-0.41)-(- \\
0.47)\end{array}$ & - & - & - \\
\hline
\end{tabular}

\section{Discussion}

The objective of the present study was to gather all the existing questionnaires available in Italian for the assessment of the upper limb, both generally and for each of its main joints (shoulder, elbow and hand/ wrist), in order to compile both the structural and psychometric characteristics of all the questionnaires, as well as to compare them, with the aim of identifying the most interesting questionnaire, based on its clinical and research use. The psychometric characteristics of the identified questionnaires generally show good or very good reliability and internal validity values. The construct validity depends on the variable to be analyzed and it is observed that there are variables with a very good correlation while others show a poor correlation (Tables 5, 6, 7 and 8). These results are similar to those observed in a previous study where the psychometric characteristics of the questionnaires published in Italian were analyzed, although for the evaluation of the lumbar and cervical spine [16].

In the scientific literature, most of the questionnaires developed to test pain, function and social influence are in English [17, 24]. They are frequently used in clinical and research fields in the Anglo-Saxon culture, and their demand is increasingly spreading all over the world [34, 35]. This leads to the problem of cultural and linguistic differences between various countries, which can pose difficulties in terms of the equivalence of translated questionnaires to the original versions [17, 24]. Therefore, validation in the desired language must comply with standards that are as homogeneous and rigorous as possible in the scientific literature $[24,35]$. The validation process must allow the different versions to be made and developed in different parts of the world, to be culturally and linguistically adapted, and to be comparable amongst themselves in order to use them for higher evaluations, such as reviews and meta-analyses [6, 36, 37].

\section{Selection and use of questionnaires in a clinical and research environment}

A total of 16 questionnaires were identified and validated in Italian for the assessment of the upper limbs, shoulder, elbow and wrist/hand. Each of these questionnaires has a series of different psychometric characteristics, as well as a different outcome variable. Therefore, it will be the clinician or researcher, depending on the outcome variable of interest, who decides which of these questionnaires best suits the needs or objectives, based on the available time, patient profile, main variable of interest, etc.

In the selection of the questionnaires, from the clinical utility point of view, there are usually two characteristics that exert a stronger influence when they are selected: time to complete the questionnaire and main outcome variable.

For the upper limb, DASH and CISSq take about 10 min to complete. The ULFI questionnaire, as in the case of DASH, measures upper limb function in people with musculoskeletal impairment, although it takes less time to be completed ( $5 \mathrm{~min}$ ), while CISSq assesses the severity of cold intolerance in a patient population with surgical repair of peripheral nerve lesions in the upper limb.

In the questionnaires aimed at evaluating the shoulders, there is enormous heterogeneity when defining the objective or the main outcome variable of the questionnaire, each of them being very specific for a specific variable. However, in the time to complete it, there is an almost generalized homogeneity, ranging between 5 and $10 \mathrm{~min}$, with the exception of the UCLA Shoulder Score, which is the one that requires the shortest time to be completed and the Rotator Cuff Quality of Life, which is, with 10-15 min, the identified questionnaire that requires the longest time to complete (Table 2).

For the elbow, only the PRTEE was selected. It takes about $10 \mathrm{~min}$ to be completed and is designed to 


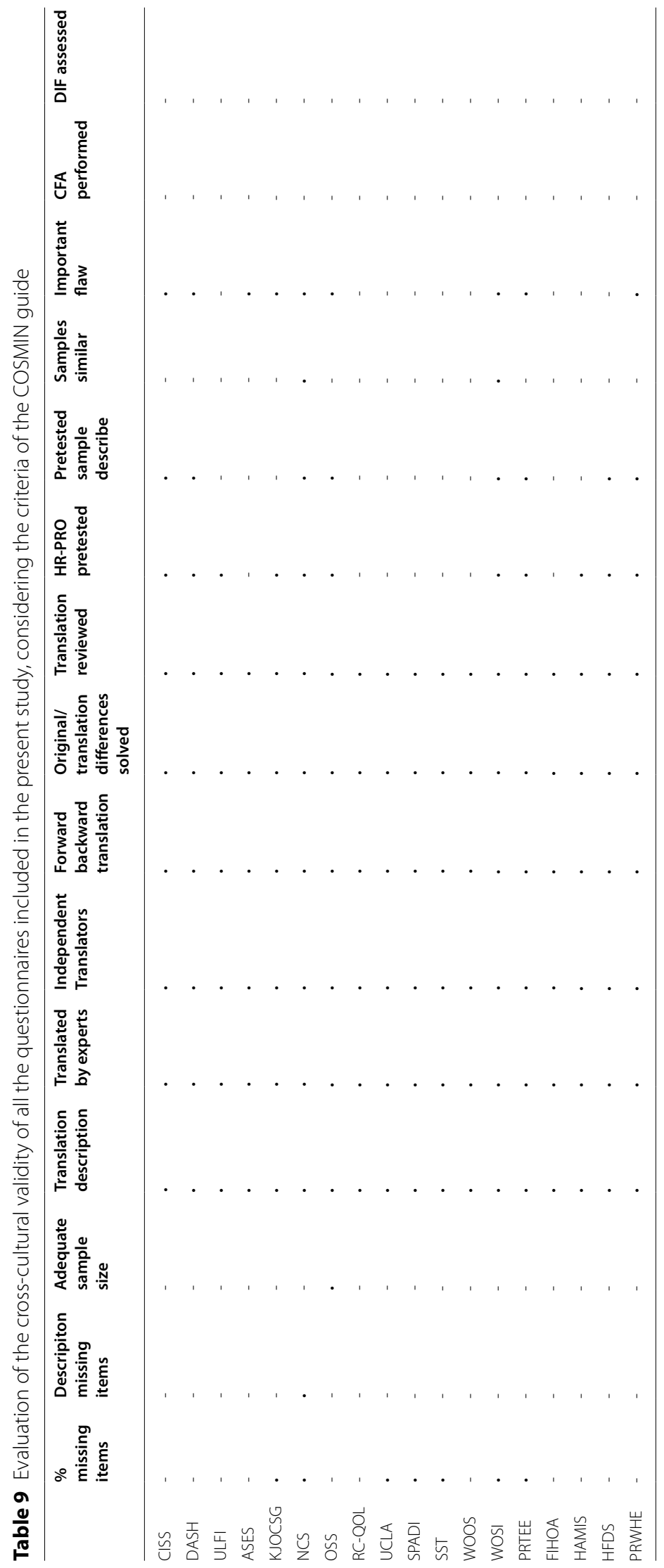


evaluate pain and disability in subjects with lateral elbow tendinopathy.

In the questionnaires aimed at evaluating the wrist, there is also a lot of heterogeneity in the main outcome variables that each questionnaire assesses, although all of them take at least $10 \mathrm{~min}$ to complete, with the exception of FIHOA [30], which requires 5 min (Table 4).

On the other hand, it is important to mention that, during the bibliographic search, it was identified that different questionnaires are aimed at fully or partially evaluating some of these regions, but whose Italian version had not been validated yet. In this sense, it would be interesting for future studies to develop Italian versions and expand the catalogue of available tools for these body regions.

\section{Psychometric characteristics of questionnaires for upper limbs}

In general, both the reliability and internal consistency of the questionnaires identified for the evaluation of the upper limbs is similar to that of their respective original versions, i.e., CISS [40], DASH [41] and ULFI [46], being comparable with other versions published in other languages, such as: the Swedish [38] and Turkish versions [39] for the CISS; Swedish [42], Danish [43] and Dutch versions [44] in the case of DASH; and Spanish [47], French [50] and Korean versions [48] for the ULFI.

Regarding the criterion validity, each questionnaire uses different reference tools. The validity of DASH is similar to that of the original English version [51] and Swedish translation [42], which uses the SF-36 [45]. The DASH questionnaire is the validation instrument for the ULFI questionnaire, whose results are in line with those of the English [46] and French versions [49] and higher than those of the Korean version [48]. Only the Spanish version uses the EQ-5D-3 [47]. For the CISS questionnaire, validity analyses were not performed for the English version [40].

The SEM value is only reported for the CISS [18] and ULFI [51] questionnaires. This parameter is reported by other studies only for ULFI. Specifically, the value is slightly higher than that of the English $[46,52]$ and Spanish versions [47] and lower than that of the French version [49].

The MDC value is only reported for the ULFI [51] and CISS [18] questionnaires. The MDC value reported in the English ULFI $[46,52]$ is lower than that reported in the Italian version [51].

\section{Psychometric variables of the questionnaires for the assessment of the shoulder}

All the questionnaires aimed at evaluating the shoulder show excellent reliability, with the exception of the
Nottingham Clavicle Score [20] and the Oxford Shoulder Score [21], which present two sub-scales with poor (0.29, NCS) and moderate (0.57, OSS) reliability levels (Table 6). When compared with the original version, some questionnaires are coherent with their Italian versions, such as the Italian UCLA scale [65, 66], KJOCSE [22], RC-QoL [26], ASES [25], WOOS [23] and WOSI [24]. However, reliability is lower than that of the original version, as is the case of SPADI [65, 67, 68]. Except for specific exceptions, all these questionnaires are also in line with other versions published in other languages, with population groups as diverse as Chinese [64], Turkish [57, 63], Korean [56, 59], Polish [60], Hebrew [77], French [61], Persian [24, 62], German [54, 58], Finnish [55] and Spanish [28, 53], among others. The fact that there are multiple versions of the same questionnaire and that, in addition, they have similar psychometric characteristics, makes it possible to compare the results of different studies, thus expanding the possibility of understanding the eventual compared results.

The same trend regarding internal consistency was observed when comparing the Italian questionnaires with the different original versions. In this sense, they are all consistent with the levels observed in the original version, as well as with different versions made in other languages, although there are specific exceptions, such as SPADI, which presents a slightly lower level with respect to that of the Dutch, German, Greek and Slovene versions [24, 69-71], and SST [65], which presents values higher than that of the Spanish and Dutch versions [69, 70].

For external validity, there is considerable consensus when it comes to selecting reference tools to calculate this variable. Specifically, there are 4 instruments that are used on a recurring basis. The SF-36 is used by ASES [25], NCS [20], OSS [21] and WOSI [24], DASH is used by KJOCSE [22], NCS [20], WOOS [23] and WOSI [24], and UCLA is used by OSS [21], SPADI [28] and SST [27].

The levels of correlation observed in the Italian versions of the questionnaires are in line with those of other versions of the selected questionnaires. In fact, the SF-36 is the questionnaire with the worst correlations with all the analyzed versions. However, in a generalized manner, the questionnaires aimed at evaluating the upper limbs in a specific way (DASH, UCLA, OSS) correlate much better both in the Italian versions and in the rest of the other versions, identifying values that range between moderate $r \geq 0.6$ and excellent $\geq 0.9$.

Most of the Italian versions of the selected questionnaires did not calculate SEM or MDC, except KJOCSE, WOOS and WOSI, with SEM values of $0.81,0.80$ and 0.71 , respectively (Table 6) and MDC values of 2.42 , 2.22 and 1.96, respectively (Table 6). However, it was 
calculated in other versions, such as in the Turkish [63] and Chinese [64] versions of RC-QoL, the Chinese [67], Greek [24] and English versions [71] of SPADI, and the Dutch version of SST [69]. This psychometric variable, in a generalized manner, is not calculated by the different versions of the selected questionnaires, except for the German version of ASES [54], the Spanish version of OSS and WOSI.

\section{Psychometric variables of questionnaires for the assessment of the elbow and comparison with other translations}

Regarding the evaluation of the elbow, only the PRTEE questionnaire was found to have an Italian version.

Reliability was similar between the Italian version and the other analyzed versions $[29,72-75]$; the value of the French version [76] is slightly lower.

Internal consistency was not reported for the Italian version [29], while all the other versions showed similar values between them [72-76].

Construct validity was assessed using correlation with DASH in all analyzed versions [72-76], whose values are similar to that of the Italian version [29].

The SEM value is reported with similar results in all analyzed versions [31, 72-74, 76], except in the Turkish [75] version, where it is not presented. Finally, the MDC value is reported with similar results only in the Dutch and French versions [72, 76].

Psychometric characteristics of questionnaires for the hand and wrist and comparison with other translations

Regarding reliability, the value of the Italian FIHOA [30] is similar to that of the Dutch and Persian versions [72, 73], while the Korean [74] and Japanese [75] versions showed slightly lower values. The reliability of the Italian HAMIS [76] is similar to that of the Brazilian version [77], while only the original English version was found for the HFDS [78] with a value similar to that of the Italian version [32]. The value of the Italian PRWHE [33] is similar to that of the Arabic, Dutch and Turkish versions [79-81], and higher than that of the Hindi version [82].

Regarding internal consistency, the value of the Italian FIHOA [30] is similar to that of all the analyzed versions [72-75]. The Italian HAMIS [76] has a value similar to that of the Brazilian version [77]. For the HFDS, the internal consistency was analyzed only for the Italian version [32]. The value of the Italian PRWHE [33] is similar to that of the Arabic and Dutch versions $[79,80]$ and higher than that of the Hindi and Turkish versions [81, 82].

Regarding construct validity, all FIHOA questionnaire versions [30, 72-75] use the SF-36 questionnaire and/or VAS, as in the case of the Italian version. The value of the Italian HAMIS [76] is similar to that of the Brazilian version [77]. For HFDS, the Italian [32] and English [78] versions used the Health Assessment Questionnaire (HAQ) to evaluate validity, showing similar results. The validity of the Italian PRWHE [33] was evaluated using the correlation with SF-36 and DASH, as in the case of the other analyzed versions [79-81], except for the Hindi version [82], with similar results.

Regarding SEM, for the FIHOA questionnaire, only the Persian version [73] was evaluated, obtaining a value of 2 . Neither the Italian nor the Brazilian version [76, 77] of HAMIS reports the SEM data. No version of HFDS reports the SEM value [32, 78]. PRWHE SEM data are reported only in the Hindi and Arabic versions $[79,82]$, with 5.4 and 3.7 , respectively.

Regarding MDC, none of the analyzed FIHOA versions report the MDC value [30, 72-75]; only the Persian version [73] reports SDC, with a value of 5.4. Neither the Italian nor the Brazilian version $[76,77]$ of HAMIS reports the MDC value. No version of HFDS reports the MDC value [32, 78]. PRWHE MDC data are reported only in the Hindi and Arabic versions [79, 82], with 12.5 and 10.2, respectively.

It is important to note that some limitations were observed in the analyzed tools. Many of them do not have important psychometric variables such as sensitivity and error measurements. Therefore, future studies should be designed to analyze these psychometric variables, which are of great importance in research, especially in the clinical practice. Moreover, it is very important to consider that Italian is a language spoken by more than 65 million people living in at least 8 different countries. Thus, it is essential to consider the cultural characteristics of each population group that could condition the interpretation of both the questions and the answers obtained. In this sense, if the sociodemographic and cultural differences are substantial, it would be necessary to develop a specific version, completely adapted to the population group of interest.

On the other hand, it would be necessary to start introducing the clinimetric analysis of construct validity. Clinimetric analysis is a recently coined term that is defined as "the science of clinical measurements" [83], and allows the identification/creation of new variables/scales in traditional assessment tools. This new approach could provide very relevant clinical information, such as the fact that the items included in a scale may belong to an underlying clinical construct/ dimension. You can also report on the degree of validity of the mean of a dimension that is being evaluated $[84,85]$. Undoubtedly, this analysis would provide a greater understanding of the scale to be evaluated, also allowing a more accurate profile of the patient under 
evaluation based on the dimensions defined according to the analysis.

\section{Conclusions}

The main conclusion that can be drawn from this study is that the Italian versions of the questionnaires show good basic structural and psychometric characteristics for the evaluation of patients with musculoskeletal disorders of the upper limb and its joints (shoulder, elbow and wrist/ hand). Italian clinicians have different instruments with psychometric characteristics that, as a rule, resemble other versions of the same questionnaire published in other languages. Therefore, these characteristics would allow a comparison of the results obtained with samples from other countries. Despite these good features, there are psychometric variables that none of the selected questionnaires include. Thus, it is necessary to carry out studies that include psychometric variables in order to make the validation process homogeneous and identical for the scientific community.

\begin{abstract}
Abbreviations
ASES: American Shoulder and Elbow Surgeons; CISSq: Cold Intolerance Symptom Severity questionnaire; COSMIN: COnsensus-based Standards for the selection of health Measurement Instruments; DASH: Disability of the arm, shoulder and hand; DN-4: Douleur Neuropathique en 4 Questions; ES: Effect size; FIHOA: Functional index for hand osteoarthritis; HAMIS: Hands mobility in scleroderma; HAQ: Health assessment questionnaire; HFDS: Hand functional disability scale; KJOCSE: Kerlan-Jobe Orthopaedic Clinic Shoulder and Elbow; MDC: Minimum detectable change; MRC: Medical research council; NCS: Nottingham Clavicle score; OSQ: Oxford shoulder questionnaire; OSS: Oxford Shoulder Score;; PRISMA: Preferred Reporting Items for Systematic Reviews and Meta-analyses; PRTEE: Patient-Rated Tennis Elbow Evaluation; PRWHE: Patient-rated wrist/hand evaluation; RC-QoL: Rotator cuff quality of life; SEM: Standard error of measurement; SF-36: Short form health survey; SPADI: Shoulder pain and disability index; SRM: Standardized response mean; SST: Simple shoulder test; UCLA: University of California-Los Angeles; ULFI: Upper Limb Functional Index; VAS: Visual analogue scale; WOOS: Western Ontario Osteoarthritis of the Shoulder; WOSI: Western Ontario Shoulder Instability.
\end{abstract}

\section{Acknowledgements}

Not applicable.

\section{Authors' contributions}

LB Study design; bibliographic search; documents selection; extraction of results; elaboration of the results; writing and designing the document. MR-M bibliographic search; extraction of results; elaboration of the results; writing and designing the document. MG-S bibliographic search; documents selection; extraction of results; elaboration of the results; writing and designing the document. AIC-V documents selection; elaboration of the results; writing and designing the document. JM-B Study design; bibliographic search; elaboration of the results; writing and designing the document. MF bibliographic search; documents selection; extraction of results; elaboration of the results; writing and designing the document. All authors read and approved the final version of the manuscript.

\section{Funding}

Not applicable.

Availability of data and materials

Not applicable.

\section{Declarations}

Ethics approval and consent to participate

Not applicable.

\section{Consent for publication}

Not applicable.

\section{Competing interests}

The authors declare that they have no competing interests.

\section{Author details}

${ }^{1}$ Terme Redi, Montecatini Terme, Italy. ${ }^{2}$ Department of Nursing and Podiatry, Faculty of Health Sciences, University of Málaga, Arquitecto Francisco Peñalosa, 3, 29071 Málaga, Spain. ${ }^{3}$ Institute of Biomedicine of Málaga (IBIMA), 29010 Málaga, Spain. ${ }^{4}$ Department of Physiotherapy, Faculty of Health Sciences, University of Málaga, 29071 Málaga, Spain. ${ }^{5}$ School of Clinical Sciences of the Faculty of Health, Queensland University of Technology, Brisbane, QLD 4000, Australia. ${ }^{6}$ Grupo de investigación Methodlogy, Methods, Models and Outcomes of Health and Social Sciences (M30), Facultad de Ciencias de la Salud y Bienestar, Universidad de Vic-Universidad Central de Cataluña (UVIC-UCC), Vic, Barcelona, Spain. ${ }^{7}$ Istituto Italiano di Tecnologia, Via Morego, 30, 16163 Genova, GE, Italy.

Received: 28 June 2021 Accepted: 31 October 2021

Published online: 22 November 2021

\section{References}

1. Luime J, Koes B, Hendriksen I, Burdorf A, Verhagen A, Miedema H, et al. Prevalence and incidence of shoulder pain in the general population; a systematic review. Scand J Rheumatol. 2004;33(2):73-81.

2. van der Heijden GJMG. Shoulder disorders: a state-of-the-art review. Best Pract Res Clin Rheumatol. 1999;13(2):287-309.

3. Bongers PM. The cost of shoulder pain at work. BMJ. 2001;322(7278):64-5.

4. Merchán-Baeza JA, González-Sánchez M, Cuesta-Vargas Al. Using smartphones to collect quantitative data on lower limb functionality in people who have suffered a stroke. J Stroke Cerebrovasc Dis. 2018;27(12):3555-62.

5. Merchán-Baeza JA, Pérez-Cruzado D, González-Sánchez M, Cuesta-Vargas A. Development of a new index of strength in adults with intellectual and developmental disabilities. Disabil Rehabil. 2019;2:1-5.

6. Gabel CP, Cuesta-Vargas A, Qian M, Vengust R, Berlemann U, Aghayev E, et al. The Oswestry Disability Index, confirmatory factor analysis in a sample of 35,263 verifies a one-factor structure but practicality issues remain. Eur Spine J. 2017;26(8):2007-13.

7. Mokkink LB, Terwee CB, Patrick DL, Alonso J, Stratford PW, Knol DL, et al. The COSMIN checklist for assessing the methodological quality of studies on measurement properties of health status measurement instruments: an international Delphi study. Qual Life Res. 2010;19(4):539-49.

8. Lewis MP, ed. Ethnologue: languages of the world. 16. ed. SIL International, Dallas. 2009.

9. Bot S, Terwee C, van der Windt DAWM, Bouter L, Dekker J, de Vet HCW. Clinimetric evaluation of shoulder disability questionnaires: a systematic review of the literature. Ann Rheum Dis. 2004;63(4):335-41.

10. Hoang-Kim A, Pegreffi F, Moroni A, Ladd A. Measuring wrist and hand function: common scales and checklists. Injury. 2011;42(3):253-8.

11. Wright RW, Baumgarten KM. Shoulder outcomes measures. J Am Acad Orthop Surg. 2010;18(7):436-44.

12. Longo UG, Franceschi F, Loppini M, Maffulli N, Denaro V. Rating systems for evaluation of the elbow. Br Med Bull. 2008;87:131-61.

13. Ashton ML, Savage-Elliott I, Granruth C, O'Brien MJ. What are we measuring? A systematic review of outcome measurements used in shoulder surgery. Arthrosc Sports Med Rehabil. 2020;2(4):e429-34.

14. Gómez-Valero S, García-Pérez F, Flórez-García MT, Miangolarra-Page JC. Assessment of cross-cultural adaptations of patient-reported shoulder outcome measures in Spanish: a systematic review. Shoulder Elbow. 2017;9(4):233-46. 
15. Velstra I-M, Ballert CS, Cieza A. A systematic literature review of outcome measures for upper extremity function using the international classification of functioning, disability, and health as reference. PM R. 2011;3(9):846-60.

16. Barni L, Freddolini M, Ruiz-Muñoz M, Cuesta-Vargas Al, GonzalezSanchez M. Italian questionnaires for the evaluation of the cervical and lumbar spine: a systematic review of the structural and psychometric characteristics. Eur J Phys Rehabil Med. 2021;57(3):376-85. <a href="https://doi.org/10.23736/S1973-9087.20.06280-2."'>10.23736/ S1973-9087.20.06280-2."

17. Padua R, Padua L, Ceccarelli E, Romanini E, Zanoli G, Amadio PC, et al. Italian version of the disability of the arm, shoulder and hand (dash) questionnaire. Cross-cultural adaptation and validation. J Hand Surg. 2003;28(2):179-86.

18. Magistroni E, Ferriero G, Peri E, Parodi G, Massazza G, Franchignoni F. Psychometric properties of the Italian version of the Cold Intolerance Symptom Severity questionnaire in upper-extremity nerve repair. Eur J Phys Rehabil Med. 2019;55(5).

19. Sartorio F, Moroso M, Vercelli S, Bravini E, Medina ME, Spalek R, et al. Crosscultural adaptation, and validity of the Italian version of the upper limb functional index (ULFI-I). G Ital Med Lav Ergon. 2015;37(2):115-9.

20. Vascellari A, Schiavetti S, Rebuzzi E, Coletti N. Translation, cross-cultural adaptation and validation of the Italian version of the Nottingham Clavicle Score (NCS). Arch Orthop Trauma Surg. 2015;135(11):1561-6.

21. Murena L, Vulcano E, D'Angelo F, Monti M, Cherubino P. Italian cross-cultural adaptation and validation of the Oxford shoulder score. J Shoulder Elbow Surg. 2010;19(3):335-41.

22. Merolla G, Corona K, Zanoli G, Cerciello S, Giannotti S, Porcellini G. Cross cultural adaptation and validation of the Italian version of the KerlanJobe Orthopaedic Clinic Shoulder and Elbow score. J Orthop Traumatol. 2017;18(4):415-21.

23. Corona K, Cerciello S, Morris BJ, Visonà E, Merolla G, Porcellini G. Crosscultural adaptation and validation of the Italian version of the Western Ontario Osteoarthritis of the Shoulder index (WOOS). J Orthopaed Traumatol. 2016;17(4):309-13.

24. Cacchio A, Paoloni M, Griffin SH, Rosa F, Properzi G, Padua L, et al. Crosscultural adaptation and measurement properties of an italian version of the western ontario shoulder instability index (WOSI). J Orthop Sports Phys Ther. 2012;42(6):559-B6.

25. Padua R, Padua L, Ceccarelli E, Bondi R, Alviti F, Castagna A. Italian version of ASES questionnaire for shoulder assessment: cross-cultural adaptation and validation. Musculoskelet Surg. 2010;94(S1):85-90.

26. Papalia R, Osti L, Leonardi F, Denaro V, Maffulli N. RC-QOL score for rotator cuff pathology: adaptation to Italian. Knee Surg Sports Traumatol Arthrosc. 2010;18(10):1417-24.

27. Marchese C, Cristalli G, Pichi B, Manciocco V, Mercante G, Pellini R, et al. Italian cross-cultural adaptation and validation of three different scales for the evaluation of shoulder pain and dysfunction after neck dissection: University of California - Los Angeles (UCLA) Shoulder Scale, Shoulder Pain and Disability Index (SPADI) and Simple Shoulder Test (SST). Acta Otorhinolaryngol Ital. 2012;32(1):12-7.

28. Torres-Lacomba M, Sánchez-Sánchez B, Prieto-Gómez V, Pacheco-daCosta S, Yuste-Sánchez MJ, Navarro-Brazález B, et al. Spanish cultural adaptation and validation of the shoulder pain and disability index, and the oxford shoulder score after breast cancer surgery. Health Qual Life Outcomes. 2015;13(1):63.

29. Cacchio A, Necozione S, MacDermid JC, Rompe JD, Maffulli N, di Orio F, et al. Cross-cultural adaptation and measurement properties of the Italian version of the patient-rated tennis elbow evaluation (PRTEE) questionnaire. Phys Ther. 2012;92(8):1036-45.

30. Gandini F, Giannitti C, Fattore G, Giordano N, Galeazzi M, Fioravanti A. Validation of an Italian version of the functional index for hand osteoarthritis (FIHOA). Mod Rheumatol. 2012;22(5):758-65.

31. Del Rosso A, Maddali-Bongi S, Sigismondi F, Miniati I, Bandinelli F, Matucci-Cerinic M. The Italian version of the Hand Mobility in Scleroderma (HAMIS) test: evidence for its validity and reliability. Clin Exp Rheumatol. 2010;28(5 Suppl 62):S42-47.

32. Ingegnoli F, Galbiati V, Boracchi P, Comi D, Gualtierotti R, Zeni S, et al. Reliability and validity of the Italian version of the hand functional disability scale in patients with systemic sclerosis. Clin Rheumatol. 2008:27(6):743-9.
33. Fairplay T, Atzei A, Corradi M, Luchetti R, Cozzolino R, Schoenhuber R. Cross-cultural adaptation and validation of the Italian version of the patient-rated wrist/hand evaluation questionnaire. J Hand Surg Eur. 2012;37(9):863-70.

34. Pynsent PB. Choosing an outcome measure. The Journal of Bone and Joint Surgery British volume. 2001 Aug;83-B(6):792-4.

35. Romanini E. Analisi dei risultati in Ortopedia: significato della prospettiva del paziente. Ital J Orthop Traumatol. 1997.

36. Cuesta-Vargas Al, González-Sánchez M. Spanish version of the screening Örebro Musculoskeletal Pain Questionnaire: a cross-cultural adaptation and validation. Health Qual Life Outcomes. 2014;12(1):157.

37. González-Sánchez M, Ruiz-Muñoz M, Li GZ, Cuesta-Vargas Al. Chinese cross-cultural adaptation and validation of the Foot Function Index as tool to measure patients with foot and ankle functional limitations. Disabil Rehabil. 2018;40(17):2056-61.

38. Carlsson I, Cederlund R, Höglund P, Lundborg G, Rosén B. Hand injuries and cold sensitivity: reliability and validity of cold sensitivity questionnaires. Disabil Rehabil. 2008:30(25):1920-8.

39. Töre NG, Gümüşsoy M, Oskay D. Validity and reliability of the Turkish version of the Cold Intolerance Symptom Severity Questionnaire. Turk J Med Sci. 2019;49(4):1221-7. https://doi.org/10.3906/sag-1808-170.

40. Irwin MS, Gilbert SEA, Terenghi G, Smith RW, Green CJ. Cold intolerance following peripheral nerve injury: natural history and factors predicting severity of symptoms. J Hand Surg. 1997;22(3):308-16.

41. Hudak PL, Amadio PC, Bombardier C. Development of an upper extremity outcome measure: the DASH (disabilities of the arm, shoulder and hand) [corrected]. The Upper Extremity Collaborative Group (UECG). Am J Ind Med. 1996;29(6):602-8.

42. Atroshi I, Gummesson C, Andersson B, Dahlgren E, Johansson A. The disabilities of the arm, shoulder and hand (DASH) outcome questionnaire: reliability and validity of the Swedish version evaluated in 176 patients. Acta Orthop Scand. 2000;71(6):613-8.

43. Schønnemann JO, Larsen K, Hansen TB, Søballe K. Reliability and validity of the Danish version of the disabilities of arm, shoulder, and hand questionnaire in patients with fractured wrists. J Plast Surg Hand Surg. 2011;45(1):35-9.

44. Veehof MM, Sleegers EJA, van Veldhoven NHMJ, Schuurman AH, van Meeteren NLU. Psychometric qualities of the Dutch language version of the Disabilities of the Arm, Shoulder, and Hand questionnaire (DASHDLV). J Hand Ther. 2002;15(4):347-54.

45. Lee J-Y, Lim J-Y, Oh JH, Ko Y-M. Cross-cultural adaptation and clinical evaluation of a Korean version of the disabilities of arm, shoulder, and hand outcome questionnaire (K-DASH). J Shoulder Elbow Surg. 2008;17(4):570-4.

46. Gabel CP, Michener LA, Burkett B, Neller A. The upper limb functional index: development and determination of reliability, validity, and responsiveness. J Hand Ther. 2006:19(3):328-49.

47. Cuesta-Vargas Al, Gabel PC. Cross-cultural adaptation, reliability and validity of the Spanish version of the upper limb functional index. Health Qual Life Outcomes. 2013;11(1):126.

48. In T-S, Jung J-H, Kim K-J, Lee C-R, Jung K-S, Cho H-Y. The reliability and validity of the Korean version of the Upper Limb Functional Index. J Phys Ther Sci. 2017:29(6):1062-5.

49. Hamasaki T, Demers L, Filiatrault J, Aubin G. A cross-cultural adaptation of the Upper Limb Functional Index in French Canadian. J Hand Ther. 2014;27(3):247-53.

50. Beaton DE, Davis AM, Hudak P, Mcconnell S. The DASH (Disabilities of the Arm, Shoulder and Hand) outcome measure: what do we know about it now? Br J Hand Therapy. 2001;6(4):109-18.

51. Sartorio F, Moroso M, Vercelli S, Bravini E, Medina ME, Spalek R, et al. Adattamento cross-culturale e validazione dell'Upper Limb Functional Index (ULFI-I). 6.

52. Gabel CP, Michener LA, Melloh M, Burkett B. Modification of the Upper Limb functional index to a three-point response improves clinimetric properties. J Hand Ther. 2010;23(1):41-52.

53. Vrotsou K, Cuéllar R, Silió F, Rodriguez MÁ, Garay D, Busto G, et al. Patient self-report section of the ASES questionnaire: a Spanish validation study using classical test theory and the Rasch model. Health Qual Life Outcomes. 2016;14(1):147.

54. John M, Angst F, Awiszus F, King GJW, MacDermid JC, Simmen BR. The American Shoulder and Elbow Surgeons Elbow Questionnaire: 
cross-cultural adaptation into German and evaluation of its psychometric properties. J Hand Ther. 2010;23(3):301-14.

55. Piitulainen K, Paloneva J, Ylinen J, Kautiainen H, Häkkinen A. Reliability and validity of the Finnish version of the American Shoulder and Elbow Surgeons Standardized Shoulder Assessment Form, patient self-report section. BMC Musculoskelet Disord. 2014;15(1):272.

56. Oh JH, Kim JY, Limpisvasti O, Lee TQ, Song SH, Kwon KB. Cross-cultural adaptation, validity and reliability of the Korean version of the KerlanJobe Orthopedic Clinic shoulder and elbow score. JSES Open Access. 2017;1(1):39-44.

57. Turgut E, Tunay VB. Cross-cultural adaptation of Kerlan-Jobe Orthopaedic Clinic shoulder and elbow score: reliability and validity in Turkish-speaking overhead athletes. Acta Orthop Traumatol Turc. 2018;52(3):206-10

58. Huber W, Hofstaetter JG, Hanslik-Schnabel B, Posch M, Wurnig C. The German version of the Oxford shoulder score?cross-cultural adaptation and validation. Arch Orthop Trauma Surg. 2004;124(8):531-6.

59. Roh YH, Noh JH, Kim W, Oh JH, Gong HS, Baek GH. Cross-cultural adaptation and validation of the Korean version of the Oxford shoulder score. Arch Orthop Trauma Surg. 2012;132(1):93-9.

60. Bejer A, Szczepanik M, Płocki J, Szymczyk D, Kulczyk M, Pop T. Translation, cross-cultural adaptation and validation of the polish version of the Oxford Shoulder Score in patients undergoing arthroscopic rotator cuff repair. Health Qual Life Outcomes. 2019;17(1):191.

61. Tuton D, Barbe C, Salmon J-H, Dramé M, Nérot C, Ohl X. Transcultural validation of the Oxford Shoulder Score for the French-speaking population. Orthop Traumatol Surg Res. 2016;102(5):555-8.

62. Naghdi S, Nakhostin Ansari N, Rustaie N, Akbari M, Ebadi S, Senobari $M$, et al. Simple shoulder test and Oxford Shoulder Score: Persian translation and cross-cultural validation. Arch Orthop Trauma Surg. 2015;135(12):1707-18.

63. Gunes T, Erkorkmaz U, Kurnaz R, Bilgic E, Asci M. Rotator cuff-quality of life scale: adaptation to Turkish. Knee Surg Sports Traumatol Arthrosc. 2015;23(2):603-7.

64. Wang W, Zhang C, Cui L, Xie Q, Jia Z, Zheng W. Reliability, validity and responsiveness of the Chinese version of the Rotator Cuff Quality of Life Index (RC-QOL) in patients with rotator cuff disorders. Puebla I, editor. PLoS ONE. 2018;13(11):e0206347.

65. Marchese C. Italian cross-cultural adaptation and validation of three different scales for the evaluation of shoulder pain and dysfunction after neck dissection: University of California - Los Angeles (UCLA) Shoulder Scale, Shoulder Pain and Disability Index (SPADI). Acta Otorhinolaryngol Ital. 2012;32(1):12-7.

66. Ellman H, Hanker G, Bayer M. Repair of the rotator cuff. End-result study of factors influencing reconstruction. J Bone Jt Surg Am. 1986;68(8):1136-44.

67. Wang W, Jia Z, Liu J, Xie Q, Cui J, Zheng W, et al. Cross-cultural adaptation and validation of the Chinese version of the shoulder pain and disability index in patients with symptomatic shoulder pain: a prospective case series. Medicine. 2018;97(26):e11227.

68. Roach KE, Budiman-Mak E, Songsiridej N, Lertratanakul Y. Development of a shoulder pain and disability index. Arthritis Care Res. 1991;4(4):143-9.

69. van Kampen DA, van Beers LWAH, Scholtes VAB, Terwee CB, Willems WJ. Validation of the Dutch version of the Simple Shoulder Test. J Shoulder Elbow Surg. 2012;21(6):808-14.

70. Membrilla-Mesa MD, Tejero-Fernández V, Cuesta-Vargas Al, ArroyoMorales M. Validation and reliability of a Spanish version of Simple Shoulder Test (SST-Sp). Qual Life Res. 2015;24(2):411-6.

71. Roddey TS, Olson SL, Cook KF, Gartsman GM, Hanten W. Comparison of the University of California-Los Angeles Shoulder Scale and the Simple Shoulder Test with the shoulder pain and disability index: single-administration reliability and validity. Phys Ther. 2000;80(8):759-68.

72. Wittoek R, Vander Cruyssen B, Maheu E, Verbruggen G. Cross-cultural adaptation of the Dutch version of the Functional Index for Hand Osteoarthritis (FIHOA) and a study on its construct validity. Osteoarthritis Cartilage. 2009;17(5):607-12.

73. Kordi Yoosefinejad A, Motealleh A, Babakhani M. Evaluation of validity and reliability of the Persian version of the functional index of hand osteoarthritis. Rheumatol Int. 2017;37(5):719-25.

74. Ahn GY, Cho S-K, Cha SJ, Nam E, Lee J-E, Dreiser RL, et al. Cross-cultural adaptation and validation of the Korean Version of the Functional Index for Hand Osteoarthritis (FIHOA). Int J Rheum Dis. 2018;21(12):2095-103.
75. Nakagawa Y, Kurimoto S, Maheu E, Matsui Y, Kanno Y, Menuki K, et al. Cross-cultural translation, adaptation and validation of a Japanese version of the functional index for hand osteoarthritis (J-FIHOA). BMC Musculoskelet Disord. 2020;21(1):173.

76. Rosso AD, Bongi SM, Sigismondi F, Miniati I, Bandinelli F, Matucci-Cerinic M. The Italian version of the Hand Mobility in Scleroderma (HAMIS) test: evidence for its validity and reliability. Clin Exp Rheumatol. 2010;28(5 Suppl 62):S42-7:7.

77. Azevedo PM, Sanson ES, Skare TL, dos Santos TAFG, Martin P. The Brazillian version of the hand mobility in scleroderma (HAMIS) test: translation and validation. Adv Rheumatol. 2019;59(1):51.

78. Brower LM, Poole JL. Reliability and validity of the Duruöz Hand Index in persons with systemic sclerosis (scleroderma): self Report of Hand Function. Arthritis Rheum. 2004;51(5):805-9.

79. Hasani FN, MacDermid JC, Tang A, Kho ME. Cross-cultural adaptation and psychometric testing of the Arabic version of the PatientRated Wrist Hand Evaluation (PRWHE-A) in Saudi Arabia. J Hand Ther. 2015:28(4):412-20.

80. Holmes WJM, Tehrani H, Liew S. Cutaneous leishmaniasis: a diagnosis of suspicion. J Hand Surg Eur. 2009;34(4):555-6.

81. Topcu DÖ, Afşar Sil. Reliability, validity, and cross-cultural adaptation study of the Turkish version of the Patient-Rated Wrist/Hand Evaluation questionnaire. Turk J Med Sci. 2019;49(2):574-82. https://doi.org/10.3906/ sag-1806-37.

82. Mehta SP, Mhatre B, MacDermid JC, Mehta A. Cross-cultural Adaptation and Psychometric Testing of the Hindi Version of the Patient-rated Wrist Evaluation. J Hand Ther. 2012;25(1):65-78.

83. Fava GA, Tomba E, Sonino N. Clinimetrics: the science of clinical measurements. Int J Clin Pract. 2012;66(1):11-5.

84. Carrozzino D, Patierno C, Guidi J, Berrocal Montiel C, Cao J, Charlson ME, Christensen KS, Concato J, De Las CC, de Leon J, Eöry A, Fleck MP, Furukawa TA, Horwitz RI, Nierenberg AA, Rafanelli C, Wang H, Wise TN, Sonino N, Fava GA. Clinimetric criteria for patient-reported outcome measures. Psychother Psychosom. 2021;90(4):222-32. https://doi.org/10.1159/ 000516599.

85. Carrozzino D, Christensen KS, Mansueto G, Brailovskaia J, Margraf J, Cosci F. A clinimetric analysis of the euthymia, resilience, and positive mental health scales. J Affect Disord. 2021;294:71-6.

\section{Publisher's Note}

Springer Nature remains neutral with regard to jurisdictional claims in published maps and institutional affiliations.

Ready to submit your research? Choose BMC and benefit from

- fast, convenient online submission

- thorough peer review by experienced researchers in your field

- rapid publication on acceptance

- support for research data, including large and complex data types

- gold Open Access which fosters wider collaboration and increased citations

- maximum visibility for your research: over $100 \mathrm{M}$ website views per year

At BMC, research is always in progress.

Learn more biomedcentral.com/submissions 